\title{
Ensino de Matemática na EJA: Betim (MG), década de 1990
}

\author{
Mathematics teaching in adult education: Betim (MG), 1990s
}

Ana Rafaela Correia Ferreira ${ }^{1}$

Maria Laura Magalhães Gomes $2^{2}$

\begin{abstract}
Resumo
Este artigo focaliza o ensino de Matemática na Educação de Pessoas Jovens Adultas e Idosas (EJA), no curso de Suplência oferecido pela Rede Municipal de Educação de Betim, Estado Minas Gerais, entre 1995 e 1999 . A fonte principal do estudo é constituída por entrevistas realizadas com oito educadores, com a utilização da História Oral como princípio teórico-metodológico. Três seções inter-relacionadas compõem a parte central do texto: a questão da relação entre o tempo disponível e o currículo da EJA, as motivações para a seleção do que seria ensinado e os conteúdos matemáticos efetivamente propostos e trabalhados. Como principais critérios norteadores, evidenciaram-se a intenção de apresentar a Matemática de forma contextualizada na vida social e em outras áreas do conhecimento; a abreviação do tempo de curso em comparação ao ensino regular, a perspectiva de continuidade dos estudos para os alunos. Na análise dos depoimentos dos entrevistados, abordam-se diversos aspectos, como a falta de materiais didáticos projetados especificamente para a EJA, as dificuldades dos estudantes em Matemática, as carências dos docentes no sentido de atender as particularidades dos sujeitos jovens, adultos e idosos.
\end{abstract}

Palavras-chave: Educação de Pessoas Jovens Adultas e Idosas (EJA); Ensino de Matemática; Rede Municipal de Educação de Betim (MG); História Oral.

\begin{abstract}
This article focuses on teaching of Mathematics in the Adults' Education in the course offered by Municipal Education Network of Betim, MG, between 1995 and 1999. The main source of the study consists of interviews with eight educators, with the use of Oral History as a theoretical-methodological principle. Three interrelated sections compose the central part of the text: the question of the relation between the available time and the curriculum for adults, the motivations for selecting the subjects to be taught and the content actually proposed and worked. The main guiding criteria of the curriculum were the presentation of Mathematics in relation to social life and other areas of knowledge; the abbreviation of school time compared to regular education, the prospect of continuing studies for students.

The analysis of the interviews emphasizes several aspects, such as the lack of teaching materials designed specifically for adults, the difficulties of students in Mathematics, the teachers' lack of attention to the particularities of young, adult and elderly people.
\end{abstract}

Submetido em: 04/06/2018 - Aceito em: 12/09/2018 - Publicado em: 13/09/2018

${ }^{1}$ Doutora em Educação pela Universidade Federal de Minas Gerais. Professora do Centro Pedagógico da Universidade Federal de Minas Gerais, Brasil. Email: anarafaelacf@yahoo.com.br

2 Doutora em Educação pela Universidade Estadual de Campinas. Bolsista de Produtividade do CNPq. Professora do Departamento de Matemática e do Programa de Pós-Graduação em Educação da Universidade Federal de Minas Gerais, Brasil. Email: mlauramgomes@gmail.com. 
Keywords: Adults Education (EJA); Mathematics teaching; Municipal Education Network of Betim (MG); Oral History.

\section{Introdução}

A década de 1990 é considerada muito promissora para a Educação de Pessoas Jovens, Adultas e Idosas (EJA). A Constituição Federal brasileira, que completa 30 anos em 2018, reconheceu a Educação Básica como um direito de todos, estendido, dessa forma, a jovens, adultos e idosos. O artigo 208, em seu inciso I, garante que é dever do Estado a "educação básica obrigatória e gratuita dos 4 (quatro) aos 17 (dezessete) anos de idade, assegurada inclusive sua oferta gratuita para todos os que a ela não tiveram acesso na idade própria" (Constituição da República Federativa do Brasil, 1988). Nesse mesmo artigo, o inciso VI assegura a "oferta de ensino noturno regular, adequado às condições do educando" (Constituição da República Federativa do Brasil, 1988)³.

Esse ordenamento jurídico, segundo Soares (2001), contribuiu para consolidar, na década de 1990, as poucas iniciativas que existiam para a EJA promovidas por administrações populares, reforçando a necessidade de que o Estado as assumisse como seu dever. A partir de então, houve uma expansão significativa no atendimento ao público jovem e adulto que não tinha acesso à educação por intermédio da institucionalização desses cursos via rede pública de ensino. A Lei de Diretrizes e Bases 9.394, de 20 de dezembro de 1996, por sua vez, reafirmou o direito de acesso dos jovens e adultos trabalhadores ao ensino básico, e a EJA passou a fazer parte da organização nacional como um modo reconhecido de educação básica (Lei 9.394, de 20 de setembro de 1996, 1996).

Ainda que essa LDB preconize a EJA como uma modalidade de ensino, devendo ser adequada às condições peculiares de estudo de seu público, muitas críticas são feitas a ela. Machado (1998), por exemplo, afirma que a EJA ficou reduzida a cursos e exames supletivos, com redução da idade mínima para prestar os exames, o que seria um incentivo para que os estudantes abandonassem as classes regulares de ensino.

No entanto, embora não se possa negar a existência de problemas, é clara a expansão da oferta de cursos de EJA. A cidade de Betim-MG, por exemplo, premida por essa demanda, também ofertou, por meio da Secretaria Municipal de Educação, um curso de EJA chamado Suplência, em caráter experimental, no período compreendido entre 1995 e 1999. Esse movimento de implantação da EJA ocorreu em concordância com outras redes municipais próximas, tais como Contagem-MG e Belo Horizonte-MG, que também assumiam projetos de EJA.

\footnotetext{
${ }^{3}$ A partir da Constituição Federal promulgada em 1988, também foi aprovada a Constituição Estadual de Minas Gerais em 1989 (Constituição do Estadual de Minas Gerais, 1989) e a Lei Orgânica de Betim em 1990 (Lei Orgânica Municipal Betim, de 21 de março de 1990, 1990).
} 
Esse curso, que funcionou em quatro escolas, oferecia aos seus educadores ${ }^{4}$ uma reunião de formação semanal, extra-turno, remunerada. $O$ objetivo dessas reuniões era planejar as atividades e os projetos a serem desenvolvidos, estudar sobre o perfil dos estudantes jovens, adultos e idosos e participar de atividades formadoras sobre o assunto.

Tendo em vista a implantação desse curso, interessou-nos ${ }^{5}$ investigar a questão: Como era trabalhada a Matemática da Suplência na Rede Municipal de Educação (RME) de Betim nesse período? Em busca de respostas, entrevistamos oito educadores que atuaram na Suplência, entre professores de Matemática, pedagogos e ex-coordenadores, utilizando a História Oral como princípio teórico-metodológico. Nossa intenção, ao apresentar e analisar relatos de educadores que trabalharam na EJA na década de 1990, é compreender o ensino de Matemática do curso, a partir do ponto de vista dos sujeitos que vivenciaram essa história.

\section{Percursos teórico-metodológicos}

A principal fonte para o desenvolvimento de nossa pesquisa foram as narrativas que elaboramos a partir das entrevistas realizadas com os educadores. Considerando essas narrativas como nossas fontes principais, buscamos elaborar uma versão para a história do ensino de Matemática na Suplência, em Betim-MG, no período entre 1995 e 1999, e nos propusemos analisar as concepções dos educadores sobre Matemática e sobre o ensino de Matemática.

O recurso para a produção das narrativas foi a História Oral, metodologia que "vincula oralidade e memória" (Garnica, 2005, p. 2). A partir da reconstituição de aspectos das histórias de vida dos sujeitos (Garnica, 2003), da descrição de suas experiências e vivências, buscamos compreender o contexto em que estavam inseridos. Nessas entrevistas, merecem atenção não somente os "fatos", mas os sentidos, os sentimentos, os significados e as interpretações que os entrevistados conferem ao que vivem ou viveram (Auarek, Nunes \& Paula, 2014).

As entrevistas que realizamos, seguindo a metodologia da História Oral, inicialmente foram transcritas e depois transformadas em textualizações que, em linhas gerais, são versões editadas das entrevistas transcritas, nas quais agrupamos tematicamente as falas gravadas e transcritas, procurando suavizar marcas da oralidade de modo a possibilitar uma leitura mais fluente. Não podemos deixar de destacar que a ação de textualizar envolve a atribuição de significado pelo pesquisador, por isso, é essencialmente humana (Garnica, 2007).

Todas as narrativas constituídas nas textualizações foram devolvidas aos sujeitos, que tiveram a oportunidade de fazer alterações, caso julgassem necessário. A versão final dessas

\footnotetext{
4 Todos eles eram portadores do grau de licenciados em Pedagogia ou em áreas disciplinares específicas, contratados ou concursados na Rede Municipal de Educação-Betim.

${ }^{5}$ Para maiores informações acerca da motivação para a pesquisa, consultar Ferreira (2016).
} 
narrativas foi publicada em Ferreira (2016), com a autorização dos depoentes e permissão para a divulgação de seus nomes.

As narrativas propiciam um amplo espectro de interpretações. Nelas, os sujeitos contaram um pouco de sua vida pessoal e profissional, falaram do funcionamento do curso de EJA e dos estudantes. Além disso, explicitaram os conteúdos escolares abordados em suas aulas, suas formas de trabalho, suas concepções sobre o processo de ensino-aprendizagem para estudantes jovens e adultos, descrevendo como acreditam que seja (ou que tenha sido) a melhor forma de trabalhar Matemática nesses cursos.

Tendo o presente como parâmetro, os depoentes, muitos anos depois, fizeram reflexões sobre o que viveram. "As lembranças, quase sempre, passam pelo crivo dos valores atuais, resultantes da inter-relação sociedade-indivíduo, que determinam um tipo de discurso, de prática, de experiência" (Garnica \& Souza, 2012, p. 105). As memórias narradas pelos colaboradores possibilitam-nos

(...) ampliar o conhecimento sobre acontecimentos e conjunturas do passado através do estudo aprofundado de experiências e versões particulares; de procurar compreender a sociedade através do individuo que nela viveu; de estabelecer relações entre o geral e o particular através da análise comparativa de diferentes testemunhos e de tomar as formas como o passado é apreendido e interpretado por indivíduos e grupos como dado objetivo para compreender suas ações (Alberti, 2004, p. 19).

Para construirmos nossa história do ensino de Matemática no curso de Suplência da RME-Betim, conversamos com oito profissionais, dos quais cinco são professores de Matemática e três são pedagogas, uma delas ex-coordenadora da EJA na Secretaria Municipal de Educação. Apresentamos, a seguir, um quadro com informações sobre os entrevistados.

Quadro 1 - Dados dos entrevistados

\begin{tabular}{|c|c|c|c|c|c|}
\hline $\begin{array}{c}\text { Colaborador } \\
\text { (a) }\end{array}$ & Formação & $\begin{array}{c}\text { Tempo de } \\
\text { atuação } \\
\text { (RME - } \\
\text { Betim) }\end{array}$ & $\begin{array}{c}\text { Tempo } \\
\text { de } \\
\text { atuação } \\
\text { (ensino } \\
\text { noturno) }\end{array}$ & $\begin{array}{c}\text { Função e } \\
\text { períodos que } \\
\text { atuou no } \\
\text { ensino } \\
\text { noturno }\end{array}$ & $\begin{array}{c}\text { Data da } \\
\text { entrevista }\end{array}$ \\
\hline $\begin{array}{l}\text { Eliana Maria } \\
\text { Batista Lima }\end{array}$ & $\begin{array}{c}\text { Graduação em } \\
\text { Pedagogia } \\
\text { (Universidade de } \\
\text { Itaúna/MG) } \\
\text { Especialização em } \\
\text { Psicopedagogia } \\
\text { (Faculdade de Pedro } \\
\text { Leopoldo) }\end{array}$ & 23 anos & 22 anos & $\begin{array}{c}\text { Pedagoga } \\
\text { desde } 1993\end{array}$ & $04 / 11 / 2014$ \\
\hline Fátima Maria & Graduação em & 23 anos & 22 anos & Professora de & $22 / 09 / 2014$ \\
\hline
\end{tabular}


DOI: https://doi.org/10.20396/zet.v26i3.8652626

\begin{tabular}{|c|c|c|c|c|c|}
\hline $\begin{array}{c}\text { Simões } \\
\text { Magalhães }\end{array}$ & $\begin{array}{c}\text { Matemática (PUC-MG) } \\
\text { Especialização em } \\
\text { Matemática e em } \\
\text { "Ensino Global"6 }\end{array}$ & & & $\begin{array}{l}\text { Matemática } \\
\text { desde } 1993\end{array}$ & \\
\hline $\begin{array}{l}\text { Lázaro } \\
\text { Mariano } \\
\text { Alves }\end{array}$ & $\begin{array}{c}\text { Graduação em } \\
\text { Matemática (FAFI - } \\
\text { Formiga/MG) } \\
\text { Especialização em } \\
\text { Educação } \\
\text { Matemática(UNI-BH) }\end{array}$ & 22 anos & 06 anos & $\begin{array}{c}\text { Professor de } \\
\text { Matemática de } \\
1994 \text { a } 1999\end{array}$ & $24 / 11 / 2014$ \\
\hline $\begin{array}{l}\text { Luiz Carlos } \\
\text { da Cunha }\end{array}$ & $\begin{array}{c}\text { Graduação em } \\
\text { Matemática (FAFI - } \\
\text { Formiga/MG) } \\
\text { Especialização em } \\
\text { Educação Matemática } \\
\text { (Faculdade de } \\
\text { Barreto/SP) }\end{array}$ & 25 anos & 10 anos & $\begin{array}{c}\text { Professor de } \\
\text { Matemática de } \\
1992 \text { a } 2001\end{array}$ & $23 / 09 / 2014$ \\
\hline $\begin{array}{l}\text { Lucinda } \\
\text { Imaculada de } \\
\text { Barcelos } \\
\text { Santos }\end{array}$ & $\begin{array}{c}\text { Graduação em } \\
\text { Matemática (Faculdade } \\
\text { de Ciências Humanas } \\
\text { de Itabira) } \\
\text { Especialização em } \\
\text { Instrumentalização } \\
\text { para o Ensino da } \\
\text { Matemática (PUC-MG) }\end{array}$ & 20 anos & 05 anos & $\begin{array}{c}\text { Professora de } \\
\text { Matemática de } \\
1999 \text { a } 2000 \\
\text { Professora } \\
\text { "formadora" } \\
\text { da equipe do } \\
\text { Ensino } \\
\text { Noturno de } \\
2001{\text { a } 2003^{7}}^{7}\end{array}$ & $24 / 09 / 2014$ \\
\hline $\begin{array}{l}\text { Maria do } \\
\text { Carmo } \\
\text { Gomes } \\
\text { Amaral da } \\
\text { Mata } \\
\text { (Carminha) } \\
\end{array}$ & $\begin{array}{c}\text { Graduação em } \\
\text { Pedagogia (FAFI-BH) } \\
\text { Especialização em } \\
\text { Metodologia do Ensino } \\
\text { Superior (UEMG) }\end{array}$ & Aposentada & 14 anos & $\begin{array}{c}\text { Pedagoga de } \\
1986 \text { a } 1992 \text { e } \\
\text { coordenadora } \\
\text { do ensino } \\
\text { noturno de } \\
1993 \text { a } 1999 \\
\end{array}$ & $09 / 12 / 2014$ \\
\hline $\begin{array}{l}\text { Mônica } \\
\text { Raquel de } \\
\text { Azevedo }\end{array}$ & $\begin{array}{c}\text { Graduação em } \\
\text { Pedagogia (PUC-MG) } \\
\text { Especialização cursada } \\
\text { no Rio de Janeiro }{ }^{8} \\
\end{array}$ & 25 anos & 26 anos & $\begin{array}{l}\text { Pedagoga de } \\
1992 \text { a } 2008\end{array}$ & $24 / 10 / 2014$ \\
\hline $\begin{array}{l}\text { Silvana } \\
\text { Aparecida } \\
\text { Ferreira } \\
\text { Bicalho } \\
\text { Carvalhaes }\end{array}$ & $\begin{array}{c}\text { Graduação em } \\
\text { Matemática (FAFI-BH) } \\
\text { Especialização em } \\
\text { Educação Matemática } \\
\text { e em Psicopedagogia } \\
\text { (UNI-BH) }\end{array}$ & 05 anos & 05 anos & $\begin{array}{c}\text { Professora } \\
\text { (contratada) de } \\
\text { Matemática de } \\
1995 \text { a } 1999\end{array}$ & 29/09/2014 \\
\hline
\end{tabular}

Fonte: Elaboração das autoras a partir de entrevistas realizadas em 2014 e 2015.

\footnotetext{
${ }^{6}$ Fátima não informou onde cursou as especializações.

${ }^{7}$ Períodos prováveis, pois a professora não soube dizer com certeza quais os intervalos em que trabalhou com o ensino noturno.

${ }^{8}$ Mônica Raquel não informou o curso e a instituição.

Zetetiké, Campinas, SP, v.26, n.3, set./dez.2018, p.629-648 
Destacamos que as narrativas dos colaboradores não são um registro único e definitivo dos fatos, mas registros de percepções daqueles que vivenciaram os processos que investigamos, no momento em que nos concederam as entrevistas. São relatos, que mostram perspectivas dos falantes, nossos depoentes, compreendidas a partir da perspectiva das pesquisadoras. Não se trata, pois, de procurar, a partir de uma narrativa específica ou de um conjunto particular de narrativas, "transcender a subjetividade dos narradores rumo a uma generalização, a uma explicação global que escape às narrações manifestadas nos depoimentos" (Garnica, 2007, p. 45), mas, sim, de escrever uma história plausível dentre tantas outras que poderiam ser contadas.

Para compreendermos o que nossos depoentes nos disseram, procuramos dialogar com textos e autores diversos, muitos deles voltados para a EJA, o currículo e a educação matemática escolar para esse público específico de estudantes. Dedicamo-nos, então, a seguir, na parte central de nosso artigo, a um tema especial da história da Suplência em Betim na década de 1990, a saber, a Matemática projetada e desenvolvida nesse curso. Três seções inter-relacionadas compõem nossa abordagem: a questão da relação entre o tempo disponível e o currículo da EJA, as motivações para a seleção do que seria ensinado e os conteúdos matemáticos efetivamente propostos e trabalhados.

\section{Currículo, ensino de Matemática e a questão do tempo na EJA}

Acreditamos que analisar os critérios utilizados para a seleção e organização dos conteúdos escolares por educadores pode contribuir para que compreendamos "a(s) concepção(ões) de currículo que norteia $(m)$ as atividades e práticas dos docentes, pois toda discussão sobre currículo perpassa pela questão de seleção e organização dos conteúdos" (Eugênio, 2004, p 152).

Santos e Paraíso (1996) salientam que a palavra "currículo" já ganhou várias definições desde sua introdução no campo pedagógico ${ }^{9}$. Em texto contemporâneo à época da Suplência, as autoras citam, por exemplo: "um elenco de disciplinas e de conteúdos" ou "um conjunto de experiências trabalhadas pela escola". Elas fazem uma análise histórica dos significados atribuídos ao "currículo" e afirmam que, na década de 1970, o currículo era entendido como a "especificação dos objetivos da educação considerados 'desejáveis' e a definição dos conteúdos a serem transmitidos na escola para se atingirem tais objetivos" (Santos \& Paraíso, 1996, p. 83). No final da década de 1980 e início da década de 1990, porém, a renovação na produção sobre currículo no Brasil conduziu à problematização do conceito "a partir de suas relações com as esferas políticas, econômicas e socioculturais, sendo entendido como todas as experiências e conhecimentos proporcionados aos estudantes no cotidiano escolar" (Santos \& Paraíso, 1996, p. 83). Na época da publicação desse trabalho,

\footnotetext{
${ }^{9}$ Segundo as autoras, o termo currículo é derivado da expressão latina curriculum e significa "pista ou circuito atlético". No entanto, essa palavra também tinha outros significados, tais como "ordem como sequência" e "ordem como estrutura".
} 
ocorria uma mudança de enfoque, argumentam as autoras. O currículo passava a ser entendido como "artefato cultural, à medida que traduz valores, pensamentos e perspectivas de uma determinada época e sociedade" (Santos \& Paraíso, 1996, p. 82).

Para nós, tem grande relevância essa concepção de currículo, à qual é pertinente agregar as considerações de Tomaz Tadeu da Silva (1999, p. 15): "O currículo é sempre o resultado de uma seleção: de um universo mais amplo de conhecimentos e saberes selecionase aquela parte que vai constituir precisamente o currículo". Essa seleção, por sua vez, estaria inevitavelmente permeada por relações de poder. Para o autor, em outro texto (Silva, 2005), é importante ver o currículo não apenas como sendo constituído de "fazer coisas", mas também como "fazendo coisas às pessoas".

O currículo é aquilo que nós, professores/as e estudantes, fazemos com as coisas, mas é também aquilo que as coisas que fazemos fazem a nós. O currículo tem que ser visto em suas ações (aquilo que fazemos) e em seus efeitos (o que ele nos faz). Nós fazemos o currículo e ele nos faz (Silva, 2005, p. 194).

As palavras de Silva (2005) chamam a atenção para o aspecto político da perspectiva de seleção de conteúdos e formas de trabalho:

Se o currículo é aquilo que fazemos com os materiais recebidos, então, apesar de todos os vínculos desses materiais com relações de poder, ao agir sobre eles, podemos desviá-los, refratá-los, subvertê-los, parodiá-los, carnavalizá-los, contestá-los. Por outro lado, se, ao produzir o currículo, somos também produzidos, é porque podemos ser produzidos de formas muito particulares e específicas. E essas formas dependem de relações específicas de poder. Flagrá-las e identificá-las constitui, assim, uma ação fundamentalmente política (Silva, 2005, p. 194).

Percebemos grande semelhança entre a concepção de Silva (2005), de que o currículo deve ser visto em suas ações e em seus efeitos, considerando seu aspecto político, e a concepção de currículo defendida por nossos colaboradores. Para nossos entrevistados, o currículo de Matemática era concebido como seleção de conteúdos, ou seja, como escolha do que seria trabalhado nas salas de aula da Suplência. A pedagoga Eliana, por exemplo, comentou $^{10}$ : Sobre os currículos, na verdade, o que havia eram ementas. Até então não havia um currículo. Ela ressaltou, juntamente com outros colaboradores, que eram elaborados alguns programas para as disciplinas que constavam na grade curricular: Português, Matemática, Ciências, Geografia e História. Até então, pelo menos no âmbito da RMEBetim, não havia uma visão de currículo mais abrangente, como a de Santos e Paraíso (1996).

Um aspecto político fundamental para o ensino de Matemática na Suplência em Betim, enfatizado por todos os educadores entrevistados, reside na redução do tempo de curso em relação ao ensino dito regular, um fator de peso imensurável na construção curricular. Os educadores salientaram que essa diminuição do tempo era aquilo que mais repercutia na organização dos programas e do ensino de Matemática. Segundo Lázaro, na RME de Betim, o curso de Suplência era semestral. Por causa disso, dessa redução de tempo, o trabalho com a Matemática tinha que ser muito bem pensado. A redução do tempo

${ }^{10}$ Destacamos com itálicos as falas dos entrevistados.

Zetetiké, Campinas, SP, v.26, n.3, set./dez.2018, p.629-648

ISSN 2176-1744 
também foi sinalizada por Silvana: Como o curso era de dois anos, não conseguiríamos fazer o que se faz em quatro anos, impossível.

A discussão acerca do tempo é muito comum na EJA, que "está quase sempre premida pelas pressões para a abreviação do processo de escolarização" (Fonseca, 1999, p. 31). O tempo é, pois, sempre tido como um dos problemas a serem enfrentados pela equipe escolar, conforme destaca a Proposta Curricular Nacional para a EJA:

"Falta tempo para se ensinar tudo que é necessário", "falta tempo para o convívio escolar mais intenso". (...) Na educação de jovens e adultos, conciliar o tempo disponível e a qualidade do ensino parece ser uma das questões a serem associadas para garantir o aprendizado dos alunos (MEC, 2002, p. 138).

Sita Sant'Anna (2013) ratifica essa ideia. Ela ressalta que a ideia de reduzir o tempo está vinculada a um discurso assistencialista de que é preciso resolver rapidamente o problema dos poucos escolarizados por meio de "uma prática compensatória e com conteúdos prioritários selecionados a serem ministrados, 'inculcados' em pouco tempo, ou seja, 'escolhese o essencial para se colocar no que falta'" (p 32).

Em virtude da menor duração do curso de Suplência em relação ao ensino regular, os professores e pedagogos deram ênfase à necessidade de se aproveitar bastante o tempo, mas em uma perspectiva diferente da aludida por Sant'Anna (2013). A professora Silvana destacou a liberdade que tinha de planejar as aulas, embora levando em conta a limitação do tempo: Tínhamos liberdade de selecionar quais eram os principais temas de cada conteúdo. Não ficávamos perdendo tempo com conteúdo muito abstrato, mas sim, tentávamos fazer com que os alunos vissem a aplicabilidade do conteúdo.

Eliana contou que se lembrava da criação de algumas ementas, com o cuidado de ter o aluno (e os conhecimentos que ele traz para a vivência da sala de aula) como parâmetro principal na seleção dos conteúdos: Discutimos vários eixos do currículo, deixando bem claro que teríamos que criar um currículo flexível, valorizar o saber que o aluno traz, não ficar impondo muita coisa e ver o que ele realmente precisa. Não poderia ser uma coisa pronta, um programa enorme de $5^{a}$ a $8^{a}$ série, porque não adianta nada... Temos que respeitar o tempo do aluno.

Fátima também explicou a organização curricular e procurou discorrer sobre como eram escolhidos os conteúdos a serem trabalhados: Na escola que eu trabalhava, ${ }^{11}$ por exemplo, a minha vivência é de lá... Éramos eu e o Máximo ${ }^{12}$; juntos nós conversávamos e decidíamos o que passar para o pessoal da noite. A gente se baseava muito no programa do diurno, tudo assim bem prático, mas não rápido. Todos os itens eram muito bem trabalhados, muitas coisas que caem em concursos. A professora salientou que, embora houvesse uma diminuição de tempo, os conteúdos não deveriam ser abordados de forma rápida. Para ela, era mais importante realizar uma abordagem aprofundada, priorizando os

\footnotetext{
${ }^{11}$ Fátima refere-se à Escola Municipal "Raul Saraiva Ribeiro", escola em que lecionou no ensino noturno por 17 anos.

${ }^{12}$ Fátima cita um colega de trabalho, também professor de Matemática.

Zetetiké, Campinas, SP, v.26, n.3, set./dez.2018, p.629-648 
conteúdos "práticos", ou seja, que tivessem alguma aplicabilidade, independentemente de qual fosse o contexto.

\section{Seleção de conteúdos de Matemática na Suplência: como e por quê}

Em vista das considerações anteriores, é relevante refletir sobre duas questões. Por que e como a seleção de conhecimentos a serem veiculados na escola era feita pelos educadores? Por que alguns conhecimentos eram considerados mais importantes do que outros?

Esses questionamentos nos direcionam aos estudos de Michael Apple ${ }^{13}$ sobre currículo. Segundo Silva (1999), na concepção de Apple, o currículo "está estreitamente relacionado às estruturas econômicas e sociais mais amplas", não sendo "um corpo neutro, desinteressado de conhecimentos" (Silva, 1999, p. 46). Na visão de Apple, o currículo é permeado por relações de poder e reflete os interesses particulares de grupos dominantes.

O Currículo nunca é simplesmente uma montagem neutra de conhecimentos, que de alguma forma aparece nos livros e nas salas de aula de um país. Sempre parte de uma tradição seletiva, da seleção feita por alguém, da visão que algum grupo tem do que seja o conhecimento legítimo. Ele é produzido pelos conflitos, tensões e compromissos culturais, políticos e econômicos que organizam e desorganizam um povo (Apple, 2000, p. 53).

Levando em conta a perspectiva de Apple (2000), é pertinente analisar a concepção dos educadores do curso de Suplência quando disseram que a seleção de conteúdos de Matemática pautava-se no pressuposto de que não deveriam ser "abstratos". Ao contrário, os estudantes da EJA deveriam perceber possibilidades de utilização do conteúdo; entre elas, estaria a sua "cobrança" em provas externas, como as de concursos públicos, por exemplo, tal como referido pela professora Fátima, cuja fala está transcrita anteriormente, e reafirmado pelo professor Luiz Carlos: (...) eu tinha a preocupação de fazer com eles alguns exercícios tipo os que a gente vê em concursos, porque eles já demonstravam interesse por isso.

A necessidade de mostrar a aplicabilidade da Matemática é muito preconizada nos estudos sobre EJA e nos documentos oficiais para o ensino de Matemática (MEC, 1998; 2002a). Podemos dizer, inclusive, que há um discurso recorrente nos estudos sobre ensino de Matemática a respeito da importância de enfatizar a aplicabilidade dessa disciplina em diversas situações cotidianas e como ferramenta para outras áreas do conhecimento. A Matemática vem ganhando espaço e sendo demandada a produzir modelos que descrevam ou que auxiliem na compreensão de fenômenos nas diversas áreas do saber, contribuindo para o campo de novos conhecimentos nessas áreas e, ao mesmo tempo, se desenvolvendo como campo de conhecimento científico (Tomaz \& David, 2008). Essas representações parece-nos terem sido assumidas pelos educadores do curso de Suplência ${ }^{14}$.

\footnotetext{
${ }^{13}$ Educador e sociólogo americano.

${ }^{14}$ Ferreira (2009) e Ferreira \& Gomes (2015) afirmam que esse discurso, inclusive, já foi incorporado também pelos estudantes da EJA.
}

Zetetiké, Campinas, SP, v.26, n.3, set./dez.2018, p.629-648

ISSN 2176-1744 
Na Proposta Curricular Nacional para o segundo segmento da EJA, a questão da importância da Matemática na educação escolar é contemplada com destaque. A Matemática é vista como "uma ciência viva, quer no cotidiano dos cidadãos quer nos centros de pesquisas, nos quais se elaboram novos conhecimentos que têm sido instrumentos úteis para solucionar problemas científicos e tecnológicos em diferentes áreas do conhecimento" (MEC, 2002a, p. 12).

Nesse documento, sobressai-se a preocupação de vincular o conhecimento matemático escolar aos conhecimentos dos estudantes, visto que "as conexões que o jovem e o adulto estabelecem dos diferentes temas matemáticos entre si, com as demais áreas do conhecimento e com as situações do cotidiano é que vão conferir significado à atividade matemática" (MEC, 2002a, p. 15).

Referindo-se ao porquê de se ensinar Matemática, Fonseca (1995) argumenta que autores da década de 1980 ressaltam o papel da disciplina para se formar um "cidadão", "ciente de seus deveres e que reivindique e defenda seus direitos, motor de sua própria transformação e sujeito da História" (Fonseca, 1995, p. 49). Segundo a autora, que chama a atenção para a Matemática como uma atividade tipicamente humana e um elemento da cultura, todo indivíduo teria uma matematicidade, característica inerente ao ser humano.

A matematicidade seria a disponibilidade, a possibilidade de a pessoa abrir-se e deixar emergir seu senso matemático e traduzi-lo em sentimento, raciocínio, ação ou representação. Essa matematicidade está presente nas diversas situações e nos orienta considerações, julgamentos e decisões (Fonseca, 1995, p. 50).

O termo matematicidade ${ }^{15}$ também é utilizado na versão preliminar do Projeto Político Pedagógico do curso de suplência (SMEC, 1996). Esse documento, intitulado "Projeto Político-Pedagógico para a Educação de Jovens e Adultos - Modalidade: Suplência de $5^{\text {a a }} 8^{\text {a }}$ séries - Rede Municipal de Betim", é datado de setembro de 1996 e foi elaborado a partir das atividades para a formação dos educadores envolvidos com o curso de Suplência, inclusive em conjunto com a assessoria externa à RME-Betim especialmente contratada para discutir sobre EJA e o perfil dos estudantes.

O horizonte principal do curso de Suplência em relação ao conteúdo a ser focalizado era o programa do ensino diurno, de modo bem "prático", como sublinhou a professora Fátima (A gente se baseava muito no programa do diurno) e foi confirmado pelo professor Luiz Carlos: A gente "enxugava" parte do currículo; deixava aqueles itens que eram julgados mais importantes, mais úteis, que eles usariam mais na rotina deles. A falta de material específico para a EJA foi o motivo evocado por Eliana para o ensino regular ser tomado como referência para a seleção de conteúdos: O professor fazia uma adaptação dos

\footnotetext{
15 Acreditamos que o uso da palavra se deve à influência de Maria da Conceição Fonseca, autora do artigo acima referido e assessora de Matemática do curso de Suplência na época em que o documento foi elaborado. Partes do texto de Fonseca (1995), inclusive, encontram-se transcritas no documento. Em especial, ele destaca a importância de uma abordagem sociocultural da matemática, buscando evidenciar o papel desse conteúdo na construção da cidadania, conforme Fonseca (1995) destacou ao se referir a estudos sobre o ensino de Matemática na década de 1980.
}

Zetetiké, Campinas, SP, v.26, n.3, set./dez.2018, p.629-648

ISSN 2176-1744 
conteúdos do ensino fundamental regular. Depois, com os $\mathrm{PCNs}^{16}$ e o $\mathrm{CBC}^{17}$, ficou mais fácil, pois havia onde consultar. Mas antes dos PCNs para a EJA ${ }^{18}$, não havia nenhum material de EJA.

O professor Luiz Carlos sublinhou como as adaptações eram feitas: [as aulas eram elaboradas] em cima do que já existia, mas adaptando para a EJA. E dentro daquele currículo, fazíamos alterações, adequações, ajeitamentos que eram necessários, mas sem sair do eixo principal. O professor disse, na época de sua entrevista, que essa atitude ainda era comum: isso acontece até hoje, dependendo você faz algumas adequações, mas dentro de um eixo principal, sem extrapolar muito e fazer uma coisa mirabolante, que não tem nada a ver, e nem sem cumprir o que precisa... Pelo menos o mínimo deve ser cumprido.

Outro ponto observado por nossos colaboradores foi o sequenciamento dos conhecimentos matemáticos escolares. Conforme disse o professor Luiz Carlos: Você pensar em sequência, saber que uma coisa depende da outra, que um conhecimento depende do outro... Isso aí contribuía muito, contribui até hoje. Você não pode ter um raciocínio muito solto, sem estar interligando um ao outro quando uma coisa depende da outra. É como você subir uma escada, é um degrau após o outro. Ele frisou a importância de se pensar os conteúdos matemáticos sempre em uma relação de continuidade: É bom quando você vê que os alunos estão começando a assimilar esse tipo de ensinamento, começando a desenvolver esse tipo de raciocínio, esse tipo de... de pensar mesmo, pensar em sequência.

Considerando a proposta da Suplência em Betim e os aspectos evocados pelos educadores em relação às razões e as maneiras de escolher os assuntos a serem abordados naquele contexto, quais conhecimentos matemáticos eram trabalhados no curso?

\section{Conteúdos matemáticos propostos e trabalhados na RME-Betim}

No documento que versa sobre a Suplência na Rede Municipal (SMEC, 1996) consta a sugestão de alguns conteúdos a serem trabalhados. Porém, conforme o documento, essa lista não teria a pretensão de se constituir um currículo, mas sim, a de atender a uma demanda dos educadores da suplência no sentido de se estabelecer um referencial mínimo para orientar o seu trabalho ${ }^{19}$. A relação inclui conteúdos de geometria; números naturais, inteiros e racionais; medidas; proporcionalidade; uma introdução à álgebra.

Há, no documento, uma seção específica para cada disciplina, que descreve os conteúdos importantes e discorre sobre sua abordagem, de acordo com cada área do conhecimento. A seção de Matemática é intitulada "Repensando o ensino de Matemática" e nela acentua-se que a Matemática é apresentada nas escolas, em geral, como corpo de conhecimentos "estático, pronto, árido, (...) essencialmente formalizado e fechado em si

\footnotetext{
${ }^{16}$ Parâmetros Curriculares Nacionais (Brasil, 1998; Brasil, 2002).

${ }^{17} \mathrm{CBC}$ - Currículo Básico Comum são as proposições curriculares e orientações pedagógicas da Rede Estadual de Educação de Minas Gerais.

18 Brasil (2002).

${ }^{19}$ A parte de Matemática desse documento foi analisada por Méri Kooro em sua dissertação (Kooro, 2006).
} 
mesmo" (SMEC, 1996, p. 80). Em sentido oposto, recomenda-se que os educadores repensem suas concepções de modo a dar sentido à Matemática ensinada.

Dois eixos importantes a se considerar no trabalho na Suplência são apontados. O primeiro deles acentua que a Matemática é uma atividade tipicamente humana e um elemento da cultura; todos os indivíduos possuem uma matematicidade que seria inerente ao ser humano. Cada grupo cultural teria suas formas de matematizar. Não haveria como os educadores ignorarem isso e não respeitarem essas particularidades.

O segundo eixo refere-se à Matemática como um instrumento de leitura e transformação da realidade. Destaca-se a necessidade de contextualizar o conhecimento matemático a ser transmitido, buscar suas origens e acompanhar sua evolução, explicitando a sua finalidade e o seu papel na interpretação e na transformação da realidade dos educandos.

Além disso, o ensino de Matemática no curso de Suplência em Betim teria dois fortes condicionantes:

- trata-se da Educação da Matematicidade de jovens e adultos trabalhadores de uma cidade predominante industrial, em cujo mercado de trabalho nossos alunos se inserem ou gostariam de se inserir;

- a escolarização proposta corresponde à da $5^{\mathrm{a}}$ a $8^{\mathrm{a}}$ séries da escola fundamental, ou seja, nossos alunos não estão aqui à procura da aquisição de um instrumental "técnico" para uso imediato na vida diária, até porque a maior parte dessas noções e habilidades de utilização mais frequente no dia a dia eles já dominam (SMEC, 1996, p. 84-85) ${ }^{20}$.

Quais eram os conteúdos escolhidos por nossos depoentes para o trabalho na Suplência? Todos os professores de Matemática que entrevistamos (Fátima, Lázaro, Lucinda, Luiz Carlos e Silvana) concordaram que a prioridade era o trabalho com conteúdos "práticos", que fizessem alguma relação com o cotidiano dos estudantes jovens, adultos e idosos. Lázaro, por exemplo, foi enfático: Eu nunca trabalhei com um conteúdo matemático puro e simplesmente, com precisão. Os professores assinalaram que, para além dos próprios conteúdos, o importante era a forma de trabalhá-los, que seria diferente em relação à adotada em outras modalidades de ensino.

Silvana demonstrou preocupação quando se referiu à dificuldade de escolher os conteúdos de Matemática a serem trabalhados na EJA, principalmente ao se levar em conta a duração do curso e as demandas e expectativas dos sujeitos jovens, adultos e idosos: $E u$ vivenciava certa angústia por ter um tempo menor para ensinar uma gama de conteúdo enorme e ainda pensar em um perfil de aluno que era diferente.

Os próprios professores da Suplência eram responsáveis por selecionar os conteúdos a serem trabalhados em suas turmas. Lucinda, por exemplo, destacou que fazia seu planejamento sozinha: $\mathrm{Na}$ verdade, o planejamento era meu, porque eu era a única

\footnotetext{
${ }^{20}$ Nota-se a repercussão direta da participação da professora Maria da Conceição Fonseca na equipe responsável pela proposta. 
professora de Matemática do noturno daquela escola, porque não eram muitas escolas que poderiam ter dois ou mais professores, normalmente era somente um professor.

Fonseca (2005) afirma que a existência de uma certa liberdade em relação aos currículos favorece "uma atitude mais autônoma na definição da programação a ser cumprida" (p. 78). Entre os conteúdos selecionados pelos professores, a preferência por conteúdos matemáticos com aplicabilidade em situações extraescolares foi unanimemente explicitada.

Assim, o professor Luiz Carlos contou: (...) a gente buscava trabalhar uma matemática assim mais usual mesmo, o mais simples possível, aquela matemática cotidiana, do dia a dia mesmo. Descrevendo os conteúdos, ele destacou: Nós priorizávamos noções de geometria, de espaço e forma, medidas e grandezas, e um pouco de álgebra também. Eram praticamente os mesmos conteúdos do ensino regular, só que de uma maneira, assim, mais enxuta. Ele acentuou a forma como trabalhava: Também era diferente a forma como a gente abordava o conteúdo com eles. Por exemplo, quando a gente falava de equações do $2^{\circ}$ grau, não era da mesma forma que você fala pra um aluno que hoje está no $9^{\circ}$ ano com 14 anos, a gente tentava esmiuçar bem mais o conteúdo.

Luiz relatou que optava por aqueles conhecimentos que tivessem maiores possibilidades de relação com situações da vida cotidiana, reafirmando a presença até mesmo de álgebra ${ }^{21}$, mesmo que fosse "um pouco" e, também, "trabalhada de forma diferente". Mesmo sem explicitar como seria a abordagem do ensino de equações do segundo grau com estudantes jovens, adultos e idosos, Luiz pareceu ter incorporado os discursos pedagógicos veiculados sobre o ensino de Matemática em geral e sobre o ensino de Matemática na EJA, que insistem na importância de mostrar a aplicabilidade dos conteúdos para os alunos e as alunas.

Lucinda relacionou a escolha dos conteúdos ao pouco tempo disponível: Como o curso era semestral, eu tinha que fazer escolhas. Ela sublinhou também a dificuldade no trabalho com álgebra: De álgebra, principalmente aquela pura, era difícil, acho que não dava para nem imaginar a gente trabalhando aquilo. Com adolescente sim, mas com o adulto não. Com os alunos mais velhos, você dava um valor numérico para ele calcular ou levava a entender o raciocínio, mas trabalhar aquela álgebra pura era mais difícil. Podemos perceber, na fala da professora, a diferença assinalada em sua concepção do trabalho docente com estudantes jovens ou adolescentes e com estudantes adultos ou idosos.

Outra ideia manifestada por essa professora foi a da contextualização, tida como imprescindível nas aulas da Suplência: Sobre o trabalho com a Matemática, você tinha que usar sempre uma Matemática contextualizada, que estivesse ali dentro da realidade deles, trazer mesmo para dentro desse contexto deles. Acho que isso não é só específico do noturno,

\footnotetext{
${ }^{21}$ Dizemos "até mesmo" porque, normalmente, quando os entrevistados descreviam os conteúdos que trabalhavam, citavam com mais frequência os que envolviam regra de três, matemática financeira ou geometria. A álgebra sempre ficava por último ou nem mesmo era mencionada.

Zetetiké, Campinas, SP, v.26, n.3, set./dez.2018, p.629-648 
independente do diurno ou do noturno você tem que contextualizar mesmo o ensino. E ̀̀ noite nem era assim, era um dever.

A professora Fátima enumerou os conteúdos que procurava contemplar em suas aulas: Os conteúdos que nós trabalhávamos envolviam números, escrita, leitura, porcentagem, regra de três... Mas essa regra de três é diferente do diurno. Ela apontou a diferença desse trabalho com adultos em relação aos adolescentes: À noite eles enxergam qualquer "quarto elemento", que pode ser uma grandeza também, como por exemplo, até eles mesmos na hora que se está fazendo um bolo, desenvolvendo uma receita. A noção deles de aumento ou diminuição das grandezas é muito mais fácil, é diferente, porque eles têm vivência ${ }^{22}$.

Similarmente a Fátima, Lucinda destacou os conteúdos que não poderiam deixar de ser trabalhados na EJA: Eu ficava mais presa nas operações, em o quê esse aluno utilizaria desse conhecimento, o que era indispensável que ele precisasse para o dia-a-dia dele. Então a gente trabalhava muito a questão das operações mesmo, do raciocínio lógico matemático, da geometria. Essa parte de números e operações era um conteúdo que não podia faltar, trabalhando muito na perspectiva de resolução de problemas. A gente sempre trabalhava as operações com base no problema exposto. A professora também relatou que insistia bastante na parte de matemática comercial e financeira: Eles tinham mais interesse nessa parte. Como era uma época em que não havia muita oferta de emprego, muitos trabalhavam independentes, eram autônomos, ou vendiam alguma coisa; eram vendedores ou então tinham um pequeno comércio. Então, a gente trabalhava muito essa questão de lucro, prejuízo... Segundo a professora, o perfil da turma era sempre levado em conta no planejamento das aulas: Quando queria trabalhar com o conjunto dos números inteiros ou iniciar uma introdução no conteúdo, então a gente sempre pegava pelo perfil da turma para então pensar em como ia ser feita a abordagem daquele conteúdo.

Já o professor Lázaro disse que sobre Matemática, não havia um objetivo específico. Porém, eu buscava um trabalho que envolvesse mais a questão da Matemática social, de inserir essa Matemática em outros contextos, de História, Geografia e Ciências, e não uma Matemática pura. Ele alegou que seu trabalho era bem aceito pelos alunos e alunas da EJA: Percebia que o aluno se sentia contemplado da maneira que a gente trabalhava.

Constatamos, portanto, na fala dos professores, a presença de elos entre o discurso da proposta oficial da RME- Betim quanto à Matemática e à seleção de conteúdos. Nesses elos, inserem-se manifestamente a questão do tempo disponível e a forte referência que os docentes têm no ensino para adolescentes e jovens.

\section{Para concluir}

\footnotetext{
${ }^{22} \mathrm{~A}$ fala de Fátima reporta-nos à questão dos "saberes de experiência feitos" (Freire, 2006). Reconhecer esses saberes dos estudantes jovens e adultos é uma das especificidades dessa modalidade de ensino (Soares \& Soares, 2014; Fonseca, 2005).

Zetetiké, Campinas, SP, v.26, n.3, set./dez.2018, p.629-648

ISSN 2176-1744
} 
Como se pode perceber, os depoimentos dos professores evidenciam que a docência em Matemática na EJA, particularmente no que diz respeito à seleção de conteúdos, é parametrizada fortemente por suas concepções quanto às diferenças entre essa modalidade e o ensino regular, em que estão envolvidos o tempo e as características de ambos os públicos. Ademais, nota-se que os docentes narraram que sua ação pedagógica se pautava pela consciência de que o público da EJA requeria atitudes diferentes em virtude de suas características. Acentuou-se, nos relatos, que a Matemática para esses estudantes precisava ser tratada de forma "mais simples", "mais esmiuçada", "mais enxuta", e seguindo as orientações das propostas curriculares voltadas para eles e elas, contextualizadas na vida social e em outras áreas do conhecimento.

Meri Kooro e Celi Lopes (2005, p. 2) ponderam que, em função da frequente redução do tempo dos cursos voltados para estudantes jovens, adultos e idosos, "as instituições e os professores se veem, muitas vezes, obrigados a fazer uma redução de conteúdos entre os já selecionados nos currículos da escola 'regular'". No entanto, Fonseca (1999) pondera que essa "busca do essencial" não precisaria se pautar pela mera exclusão de conteúdos mais sofisticados. Como vimos, foi frequente, nas narrativas dos professores, a explicitação da álgebra como um desses conteúdos, o que nos indica a necessidade de desenvolvimento de estudos quanto à abordagem dos conhecimentos algébricos de modo a torná-los mais significativos para os estudantes da EJA do que têm sido quando os parâmetros são dados pelo ensino regular.

Devemos ponderar que as ideias de "mais enxuto", "mais simples", "mais esmiuçado", sublinhadas para o tratamento dos conteúdos na EJA, porém, ecoam representações de que os sujeitos adultos e idosos apresentam maior dificuldade de aprendizagem do que os adolescentes ou jovens.

Está implícita, pois, certa incredulidade quanto às capacidades de aprendizagem dos estudantes jovens, adultos e idosos, o que reflete a existência de uma expressão pessimista já existente no senso comum (Fonseca, 2005). No entanto, Oliveira (1999) enfatiza que a etapa da vida em que se encontra o sujeito adulto propicia que ele traga consigo "diferentes habilidades e dificuldades (em comparação com a criança) e, provavelmente, maior capacidade de reflexão sobre o conhecimento e sobre seus próprios processos de aprendizagem" (Oliveira, 1999, p. 60-61).

Certos enunciados proferidos pelos docentes chamam a atenção para outro aspecto: a ideia de organização linear dos conhecimentos matemáticos, uma vez que cada conhecimento requer o domínio de pré-requisitos. Pires (2000) explica que nessa concepção de organização dos conhecimentos são fixados marcos temáticos a serem percorridos sequencialmente. É um caminho "cujo percurso é composto de passos, cuja lei de sucessão é ir do mais simples para o mais complexo (às vezes entendida como ir do mais concreto para o mais abstrato)" (Pires, 2000 , p. 67). Obedecer a esse sequenciamento coloca sob suspeita a apresentação do conhecimento matemático, justificado pela ideia de que "é preciso garantir tantos e tais prérequisitos para seguir adiante" (Fonseca, 2005, p. 67). 
Para o professor Luiz Carlos, que se referiu especificamente ao sequenciamento do conteúdo, seria um bem que os estudantes conseguissem apropriar-se dessa sucessão. Segundo Auarek (2000), a ideia de que a aprendizagem deve acontecer "degrau por degrau", seguindo um roteiro previamente estabelecido, é uma particularidade do ensino de Matemática na escola. A mesma ideia é comentada por Pires (2000): "Ao desenvolverem seu trabalho em sala de aula, tanto os elaboradores de currículos de Matemática quanto os professores se empenham em organizá-los segundo uma 'estrutura' lógica, linear: cada assunto supõe conhecidos assuntos precedentes" (p. 67).

Apesar de essa concepção ser comumente manifestada pelos professores de Matemática em geral, julgamos que ela tem uma repercussão, na EJA, talvez mais forte do que no ensino regular, devido à sua interferência quando se leva em consideração a premência do tempo na educação escolar daqueles que não tiveram outra possibilidade de frequentar as salas de aula.

A carência de materiais didáticos projetados especificamente para a EJA foi outra dimensão que se sobressaiu nos relatos de nossos colaboradores. Paula Adelino e Maria da Conceição Fonseca (2014) afirmam que, como somente em 2007 foi criado o Programa Nacional do Livro Didático para a Alfabetização (PNLA) e apenas em 2011 foi estendida a distribuição de livros didáticos a todo o Ensino Fundamental da EJA, ainda é incipiente o número de trabalhos que tomam os materiais didáticos para a EJA como objeto de estudo. Isso nos leva a considerar que a alternativa que restava aos professores que entrevistamos seria mesmo a adaptação dos materiais disponíveis para crianças e adolescentes. Além disso, aqui se torna mais uma vez crucial a questão do tempo, agora no que diz respeito à disponibilidade dele para os docentes na preparação de suas aulas, e é pertinente lembrar, também, a falta de uma formação inicial, ainda nos cursos de graduação em Licenciatura, para atuar na EJA, o que "restringe suas possibilidades e recursos para elaboração de estratégias didáticas e de materiais para os alunos" (Adelino \& Fonseca, 2014, p. 183).

Notamos, ainda, nas falas de nossos entrevistados, que o reconhecimento da relevância de estudar Matemática na EJA - tanto de estudantes quanto por professores - foi quase sempre acompanhado da visão dos conhecimentos matemáticos como difíceis, quando nos foi dito que os alunos apresentavam muita dificuldade em assimilação e compreensão do conteúdo. Alguns colaboradores realçaram essa ideia, revelando que os discentes para quem lecionavam temiam essa disciplina, mesmo "convencidos" de seu valor. Na tentativa de vencer essa resistência, uma das estratégias mais aludidas pelos educadores foi a de abordar conteúdos com maior aplicabilidade no cotidiano, associando-os às práticas sociais do dia a dia. Essa, inclusive, foi a principal perspectiva apresentada por eles quando demandados a contar sobre a seleção de conteúdos nos cursos de EJA: escolhiam assuntos que tivessem maior aporte nas vivências do público para o qual essa modalidade de ensino era destinada.

Assim sendo, os principais critérios a serem levados em conta nessa seleção eram: a relação desses conteúdos com o cotidiano dos estudantes; a perspectiva de continuidade dos estudos para além do Ensino Fundamental e a abreviação do tempo de curso. Na perspectiva 
de que os educadores tinham liberdade para escolherem entre os conhecimentos que "deveriam" ser ou não abordados, não podemos desconsiderar as relações de poder que envolvem os processos de seleção dos conteúdos a serem trabalhados nessa modalidade de ensino, que envolve concepções de mundo, de escola, do público da EJA e de Matemática. Não se trata, pois, de uma decisão neutra e desinteressada (Apple, 2000; Silva, 1999). Como foi explicitado por Apple (1997), qualquer seleção dos conteúdos considerados mais importantes e legítimos é permeada por relações de poder: "(...) o que é considerado como conhecimento legítimo é o resultado de complexas relações de poder e lutas entre grupos de classe, raça, gênero e religião identificáveis. Assim, educação e poder são termos de um par indissociável" (Apple, 1997, p. 74).

Finalizando, avaliamos que as narrativas dos educadores mostraram sua consciência quanto a suas próprias carências relacionadas à busca de reconhecer e atender as particularidades dos sujeitos jovens, adultos e idosos. Tendo que atender a uma demanda para a qual sua formação acadêmica inicial e sua experiência docente prévia não se constituíam um alicerce seguro, esses professores, na maior parte das vezes, adotaram práticas pedagógicas muito semelhantes às realizadas no ensino regular, mesmo percebendo claramente sua impropriedade para o público da EJA.

\section{Referências}

Adelino, P. R. \& Fonseca, M. C. F. R. (2014). Matemática e texto: práticas de numeramento num livro didático da educação de pessoas jovens e adultas. Revista Brasileira de Educação, 19(56), 181-200.

Alberti, V. (2004). Manual de História Oral. Rio de Janeiro, FGV.

Apple, M. W. (1997). Conhecimento oficial: A educação democrática numa era conservadora. Petrópolis: Vozes.

Apple, M. W. (2000). Política cultural e educação. São Paulo: Cortez.

Auarek, W. A. (2000). A superioridade da matemática escolar: um estudo das representações deste saber no cotidiano da escola. Dissertação de Mestrado em Educação: Universidade Federal de Minas Gerais.

Auarek, W. A., Nunes, C. M. \& Paula, M. J. (2014). Pesquisa e formação com professores Contribuições dos estudos da narrativa. In: Souza, J. V., Diniz, M. \& Oliveira, M. G. Formação de professores(as) e condição docente. Belo Horizonte, MG: UFMG.

Constituição da República Federativa do Brasil. (1988). Brasília, DF.

Constituição do Estadual de Minas Gerais. (1989). Retirado em 17 de fevereiro, 2014, de: <http://www.almg.gov.br/opencms/export/sites/default/consulte/legislacao/Downloads/p dfs/ConstituicaoEstadual.pdf $>$.

Eugênio, B. G. (2004). O currículo na educação de jovens e adultos: entre o formal e o cotidiano numa escola municipal em Belo Horizonte. Dissertação de Mestrado em Educação: Pontifícia Universidade Católica de Minas Gerais. 
Ferreira, A. R. (2009). Práticas de numeramento, conhecimentos cotidianos e escolares em uma turma de Ensino Médio da Educação de Pessoas Jovens e Adultas. Dissertação de Mestrado em Educação: Universidade Federal de Minas Gerais.

Ferreira, A. R. C. (2016). Educação de Pessoas Jovens e Adultas em Betim (MG), 19882007: perspectivas de educadores e professores de Matemática. Tese de Doutorado em Educação, Universidade Federal de Minas Gerais.

Ferreira, A. R. C. \& Gomes, M. L. M. (2015). Ensinar Matemática para Pessoas Jovens e Adultas: concepções dos educadores da rede municipal de Betim. História Oral, 18(2), $55-82$.

Fonseca, M. C. F. R. (1995). Por que ensinar Matemática. Presença Pedagógica, 1(2), 46-54.

Fonseca, M. C. F. R. (1999). O ensino de matemática e a Educação Básica de Jovens e Adultos. Presença Pedagógica, 5(27), 28-37.

Fonseca, M. C. F. R. (2005). Educação Matemática de Jovens e Adultos - Especificidades, desafios e contribuições (3a ed.). Belo Horizonte: Autêntica.

Freire, P. (2006). Pedagogia da esperança (13a ed.). Rio de Janeiro: Paz e Terra.

Garnica, A. V. M. (2003). História Oral e Educação Matemática: de um inventário a uma regulação. Zetetike, 11(19), 09-55.

Garnica, A. V. M. (2005). A História Oral como um recurso para a pesquisa em Educação Matemática: um estudo do caso brasileiro. Anais do V CIBEM, Porto, Portugal, 1, 01-12.

Garnica, A. V. M. (2007). Manual de História Oral em Educação Matemática: outros usos, outros abusos. Anais do Seminário Nacional de História da Matemática, Guarapuava, PR, Brasil.

Garnica, A. V. M. \& Souza, L. A. de. (2012). Elementos de História da Educação Matemática. São Paulo: Cultura Acadêmica.

Kooro, M. B. (2006). Uma análise curricular da Matemática na Educação de Jovens e Adultos. Dissertação de Mestrado em Ensino de Ciências e Matemática, Universidade Cruzeiro do Sul.

Kooro, M. \& Lopes, C. Produzindo significados nas aulas de matemática da EJA: uma análise curricular. Anais do XVIII Encontro Regional de Professores de matemática, Campinas, SP, Brasil. Retirado em 19 de janeiro, 2016, de: www.ime.unicamp.br/erpm2005/ anais/c11.pdf.

Lei 9.394, de 20 de setembro de 1996. (1996). Estabelece as diretrizes e bases da educação nacional. Brasília, DF.

Lei Orgânica Municipal Betim, de 21 de março de 1990. (1990). Retirado em 17 de fevereiro, 2014, de: <http://www. betim.mg.gov.br/ARQUIVOS_ANEXO/Lei\% 20Organica\%20de\%20Betim;07384213;20121101.pdf>.

Machado, M. M. (1998). A trajetória da EJA na década de 90: políticas públicas sendo substituídas por solidariedade. Anais da $21^{a}$ Reunião Anual da ANPEd, Caxambu, MG Associação Nacional de Pós-Graduação em Educação, Brasil.

Ministério da Educação (MEC). (1998). Parâmetros curriculares nacionais: Matemática. Brasília, DF: Ministério da Educação.

Zetetiké, Campinas, SP, v.26, n.3, set./dez.2018, p.629-648

ISSN 2176-1744 
Ministério da Educação (MEC). (2002). Proposta Curricular para a Educação de Jovens e Adultos: Segundo Segmento do Ensino Fundamental: $5^{\text {a }}$ a $8^{\mathrm{a}}$ série - Introdução. Brasília, DF: Secretaria de Educação Fundamental.

Ministério da Educação (MEC). (2002a). Proposta Curricular para a Educação de Jovens e Adultos: Segundo Segmento do ensino fundamental: $5^{\mathrm{a}}$ a $8^{\mathrm{a}}$ série - Matemática, Ciências, Arte e Educação Física. Brasília, DF: Secretaria de Educação Fundamental.

Oliveira, M. K. (1999). Jovens e adultos como sujeitos de conhecimento e aprendizagem. Revista Brasileira de Educação, 12, 59-73.

Pires, C. M. C. (2000). Currículos de matemática: da organização linear à ideia de rede. São Paulo: FTD.

Sant'anna, S. M. L. (2013). Os discursos da burocracia nas perguntas dos professores da educação de jovens e adultos. EJA em Debate, 2(3), 29-40.

Santos, L. L. P. \& Paraíso, M. A. (1996). Dicionário Crítico da educação. Currículo. Presença Pedagógica, 2(7), 82-84.

Silva, T. T. (1999). Documentos de identidade - Uma introdução às teorias do currículo. Belo Horizonte: Autêntica.

Silva, T. T. (2005). Currículo e Identidade Social: Territórios Contestados. In: Silva, T. T. Alienígenas na sala de aula: uma introdução aos estudos culturais em educação (5a ed.). Petrópolis: Vozes.

Secretaria Municipal de Educação e Cultura (SMEC) (1996). Projeto político-pedagógico para a educação de jovens e adultos: modalidade: suplência de quinta a oitava séries: rede municipal de Betim: versão preliminar. Betim.

Soares, L. J. G. (2001). As políticas de EJA e as necessidades de aprendizagem dos jovens e adultos. In Ribeiro, V. M. Educação de jovens e adultos: novos leitores, novas leituras. Campinas: Mercado de Letras.

Soares, L. J. G. \& Soares, R. C. E. S. (2014). O Reconhecimento das Especificidades da Educação de Jovens e Adultos: Constituição e Organização de Propostas de EJA. Archivos Analíticos de Políticas Educativas / Education Policy Analysis Archives, 22(66), 1-25.

Tomaz, V. S. \& David, M. M. S. (2008). Interdisciplinaridade e aprendizagem da Matemática em sala de aula. Belo Horizonte: Autêntica.

\section{Fontes orais}

Alves, Lázaro Mariano. [2014]. Entrevistadora: Ana Rafaela Correia Ferreira. Betim, 24 nov. 2014.

Azevedo, Mônica Raquel de. [2014]. Entrevistadora: Ana Rafaela Correia Ferreira. Betim, 24 out. 2014.

Carvalhaes, Silvana Aparecida Ferreira Bicalho. [2014]. Entrevistadora: Ana Rafaela Correia Ferreira. Betim 29 set. 2014. Disponível em Ferreira (2016).

Cunha, Luiz Carlos da. [2014]. Entrevistadora: Ana Rafaela Correia Ferreira. Betim, 23 set. 2014. 
DOI: https://doi.org/10.20396/zet.v26i3.8652626

Lima, Eliana Maria Batista. [2014]. Entrevistadora: Ana Rafaela Correia Ferreira. Betim, 4 nov. 2014.

Magalhães, Fátima Maria Simões. [2014]. Entrevistadora: Ana Rafaela Correia Ferreira. Betim, 22 set. 2014.

Mata, Maria do Carmo Gomes Amaral da. [2014]. Entrevistadora: Ana Rafaela Correia Ferreira. Betim, 9 dez. 2014.

Santos, Lucinda Imaculada de Barcelos. [2014]. Entrevistadora: Ana Rafaela Correia Ferreira. Betim, 24 set. 2014. 